\title{
Trans-catheter aortic valve implantation: Contemporary practice and the future
}

\author{
Omar Aldalati, Philip MacCarthy, Rafal Dworakowski \\ Kings College Hospital, London, United Kingdom
}

\begin{abstract}
With increasing life expectancy, the epidemic of valvular heart disease, especially aortic stenosis, is becoming more prevalent. Transcatheter aortic valve implantation (TAVI) has emerged as an alternative therapy for patients with significant aortic valve disease. It offers a less invasive procedure in comparison to surgical aortic valve replacement and an attractive substitute from the patient's perspective. The evidence for TAVI in inoperable and high risk surgical patients is now established and in the intermediate risk group has been accumulating rapidly and is looking favourable for TAVI.

However, the full 'TAVI story' is still unfolding. Technological advances in devices and delivery systems are evolving with the aim to improve the function and durability of TAVI and to simplify the procedure while enhancing safety. The incidence of vascular injury and pacemaker requirement post TAVI remains an issue and further development in this regard is therefore of utmost importance, particularly as lower risk and potentially younger patients are treated. Moreover, the evidence concerning long-term durability of the TAVI prostheses continues to accumulate. Whilst TAVI is proving to be an invaluable tool for inoperable and high risk patients, more trial evidence is needed before it encompases lower risk populations and moreover, its use as a first line treatment worldwide in most healthcare systems is limited by the costs associated with the prosthesis. (Cardiol J 2017; 24, 2: 206-215)
\end{abstract}

Key words: trascatheter aortic valve implantation, surgical aortic valve replacement, evidence-base, complication, cost-effectiveness

\section{Introduction}

Life expectancy in Europe is still on the rise. In 2000, the average life expectancy in the United Kingdom was 78 years but by 2013 it reached 81.1 years [1]. With advancing age, the prevalence of certain diseases is changing. D'Arcy et al. [2] spoke of the "next cardiac epidemic" in 2011 due to the increasing prevalence of valvular heart disease, particularly aortic stenosis (AS), observed with the ageing population. The prevalence of any degree of calcific, degenerative AS consists of up to $40 \%$ of people aged 80 years and over [3]. More importantly, severe symptomatic AS carries a poor prognosis if left untreated. With the advancement of trans-catheter techniques, a lower complication profile and increased world-wide availability has meant that more patients are being referred for consideration of this treatment. Trans-catheter aortic valve implantation (TAVI) is already the mainstream therapy for inoperable and high risk AS patients. A large number of patients have received this treatment as it has evolved over the past 10 years and in Germany in 2015, more patients with aortic valve disease received a TAVI rather than surgical aortic valve replacement (sAVR). In this article, some light is shed on the most recent advances and where the future may lie.

Address for correspondence: Rafal Dworakowski, MD, PhD, Consultant Cardiologist, Department of Cardiology, King's Health Partners, King's College Hospital, Honorary Senior Lecturer Kings College London, Denmark Hill, SE5 9RS, London, United Kingdom, tel: 0044-20-3299-3379, fax: 0044-20-3299-3489, e-mail: rdworakowski@nhs.net

Received: 06.12.2016

Accepted: 09.01.2017 
Table 1. Summary of European Society of Cardiology and American Heart Association guidelines that encompass transcatheter aortic valve implantation (TAVI).

\begin{tabular}{|c|c|c|c|}
\hline Recommendation & Class & Level & Year \\
\hline \multicolumn{4}{|l|}{ European Society of Cardiology } \\
\hline $\begin{array}{l}\text { TAVI is indicated in patients with severe symptomatic AS who are not suitable } \\
\text { for AVR as assessed by a 'Heart Team' and who are likely to gain improvement } \\
\text { in their quality of life and to have a life expectancy of more than } 1 \text { year after } \\
\text { consideration of their comorbidities }\end{array}$ & 1 & B & 2012 \\
\hline $\begin{array}{l}\text { TAVI should be considered in high-risk patients with severe symptomatic AS who } \\
\text { may still be suitable for surgery, but in whom TAVI is favoured by a 'Heart Team' } \\
\text { based on the individual risk profile and anatomic suitability }\end{array}$ & Ila & B & 2012 \\
\hline \multicolumn{4}{|l|}{ American Heart Association } \\
\hline $\begin{array}{l}\text { TAVI is recommended in patients who meet an indication for AVR who have } \\
\text { prohibitive risk of surgical AVR and a predicted post-TAVR survival }>12 \text { months }\end{array}$ & I & $B$ & 2014 \\
\hline $\begin{array}{l}\text { TAVI is a reasonable alternative to surgical AVR in patients who meet an indication } \\
\text { for AVR and who have high surgical risk for surgical AVR }\end{array}$ & Ila & B & 2014 \\
\hline $\begin{array}{l}\text { TAVI is NOT recommended in patients in whom existing comorbidities would } \\
\text { preclude the expected benefit from correction of AS }\end{array}$ & III & B & 2014 \\
\hline
\end{tabular}

AS - aortic stenosis; AVR - aortic valve replacement; TAVR — transcatheter aortic valve replacement

\section{Current utility of trans-catheter aortic valve intervention}

Transcatheter aortic valve implantation represents one of the most significant technological advances made in cardiovascular medicine over the last decade. Since TAVI was first described by Alan Crieber in 2002, it has made its way into the European Society of Cardiology [4] and American Heart Association guidelines [5] (Table 1) and has become the 'standard of care' for inoperable and high risk groups of patients with severe AS. Table 1 summarizes the current guidelines that refer to TAVI.

In the United Kingdom 3,980 TAVIs were performed before 2012 and the number has increased dramatically since with more than 1800 cases done during 2014 alone [6]. Whilst in Germany 15,964 were done between 2011 and 2013 [7], in France 3,972 [8], between 2010 and 2012 and in the United States 12,182 TAVIs were performed between November 2011 and June 2013 [9]. Conversely, the Asian TAVR registry suggested smaller numbers of cases performed in comparison to Europe and the United States with 848 cases done in 5 Asians countries between March 2011 and September 2014 [10]. This was largely due to regulatory issues. It is noteworthy that the number of TAVIs performed in Germany since 2013 has surpassed the number of isolated sAVR cases [11]. Figure 1 summarizes the upward trend of TAVI in Europe per million population as per 2011 [12]; It also demonstrates the differences between different health care systems.

\section{Case selection}

Whilst there are some variations among centres/countries, the overall care pathway of patients undergoing TAVI is relatively standardized. Decision-making in the investigation and treatment of these patients is achieved with the 'Heart Team', a multidisciplinary group of interventional cardiologists, cardiothoracic surgeons, imaging specialists, anaesthesiologists and care-of-theelderly physicians.

Once a suitable patient is identified, he or she completes a thorough work-up that includes multiple imagining modalities including trans-thoracic echocardiography, three-dimensional (3D) assessment of the aortic annulus (using transesophageal echocardiography or cardiac computed tomography [CT]), CT aortogram and peripheral angiography, coronary angiography and pulmonary function testing. Key steps in pre-operative imaging include assessment of: aortic valve morphology, distribution and extent of valve calcification, annular dimensions, dimensions of the sinuses and sinotubular function, distance of the coronary ostia to the aortic annulus, and peripheral artery diameter, calcification and tortuosity.

Annular dimensions are key measurements in TAVI valve sizing. Choosing the correct valve size is important as undersizing the prosthesis can result in device migration and embolization or significant paravalvular aortic leak (PVL). On the other hand, oversizing increases the risk of life threatening complications such as annular rupture and the risk of vascular injury as bigger 


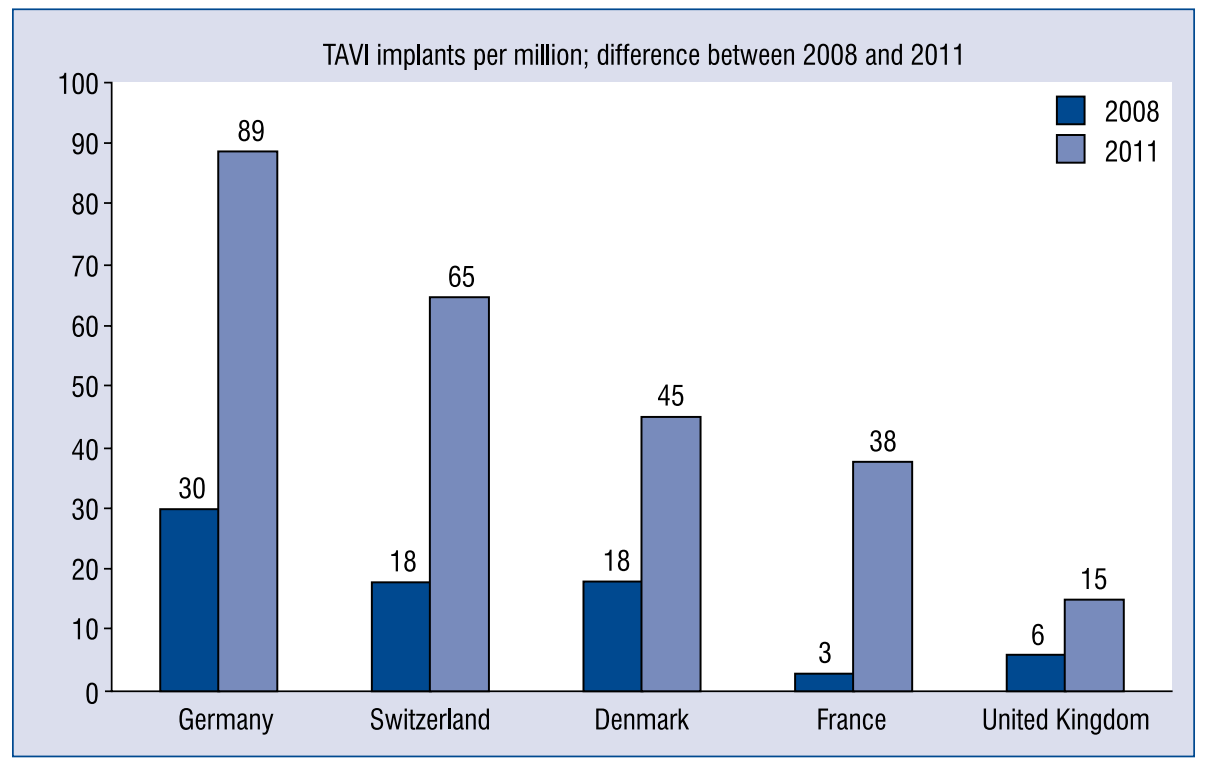

Figure 1. Summary of the upward trend of transcatheter aortic valve implantation (TAVI) in Europe per million population as per 2011.

delivery systems are needed. Inaccurate valve sizing is also associated with altered valve mechanics. Consequent under- or over-expansion of the valve leads to redundancy of leaflet tissue or leaflet noncoaptation resulting in transvalvular regurgitation.

The aortic valve annulus is defined as a virtual plane at the level of the hinge points of the three cusps and in the majority of cases is elliptical. Therefore, the use of a 3D imaging modality that allows measurements of the annulus diameter in two orthogonal plane as well as measurements of the perimeter and area is essential, and thus allows for calculation of the 'virtual' annulus diameter.

Many centres perform peripheral 3D constructed CT and peripheral angiography to assess the suitability of aorto-ileofemoral arterial system for trans-femoral TAVI. The default route for TAVI is trans-femoral and as such the numbers of nontrans-femoral cases (subclavian, trans-apical and trans-aortic) have declined in recent years.

Once the valve is implanted, operators check for any vascular injury, conduction defects, aortic regurgitation or pericardial effusion. The absence of complications would then herald the end of the procedure and the patient is then transferred usually to a level 2 care facility for monitoring. Most patients are being considered for early discharge (by day 3 ) if no further complications arise. Subsequent to discharge, patients usually have follow up at 4-6 weeks with echocardiography and electrocardiogram, and then annually thereafter.

\section{Current devices}

Whilst there are several TAVI valves in use worldwide, the two prostheses that are supported by the largest body of evidence and experience are: 1) the balloon expanding Edwards SAPIEN (Edwards Lifesciences, Irvine, CA, USA) and 2) the self-expanding Medtronic CoreValve (Medtronic, Minneapolis, MN, USA). They have different characteristics, anatomical requirements and echocardiographic appearances but they both provide excellent outcomes with their latest generations, the Sapien 3 and Evolute R.

The original Edwards SAPIEN was a balloon expandable device that had a stainless steel support frame with a bovine pericardial valve and a fabric skirt within it. This device was implanted via a transfemoral or transapical/transaortic approach. The Sapien XT (made of a cobalt-chromium alloy) was delivered on a more sophisticated, lowerprofile delivery system. The third generation of the Edwards SAPIEN valve, Sapien 3 has an additional outer skirt that has minimized PVL. It also has the advantage of an even smaller and 'double flexing' delivery system - the 'Commander' ${ }^{\mathrm{Tm}}$.

The self-expanding CoreValve is self-centering and partially repositionable. It is made of a nitinol stent with porcine pericardial leaflets. The nitinol stent has three zones. The lower zone that applies high radial forces within left ventricular outflow tract (LVOT) and the annulus anchoring the valve, 
the middle zone that carries a controlled force to avoid jailing the coronary ostia and an upper zone with low radial forces which functions to orient the valve in the direction of aortic root axis. The valve is intended to sit in a supra-annular position. The second generation, Evolut $\mathrm{R}$ valve, has a smaller delivery system, a lower frame height, fully recapturable and repositionable and available for transfemoral or transaortic routes.

The ideal TAVI valve would be low profile, have minimal risk of PVL and would be fully repositionable/retrievable. Newer generation, commercially available devices, have gone some way to achieving these goals.

The Lotus Valve (Boston-Scientific, Natick, Massachusetts, USA) is pre-mounted on the delivery system. It can be retrieved, repositioned and redeployed any time prior to release. It is delivered via the trans-femoral approach only and consists of a woven nitinol frame with valve leaflets of bovine pericardium. The ventricular portion of the valve is surrounded by an adaptive seal. On deployment, it shortens mechanically in a controlled way, providing additional radial strength compared to traditional self-expandable nitinol devices. The Lotus valve carries a higher rate of post procedural pacemaker requirement $[13,14]$.

Direct Flow (Direct Flow Medical, Santa Rosa, CA, USA) is a self-expanding valve with a novel metal free 'double ring' design with two aortic (upper) and ventricular (lower) inflatable rings. The rings contain non-compliant angioplasty balloon technology and are connected by a tubular bridging system. Each ring can be pressurised (through the normal saline/contrast) independently to allow for inflating/deflating the rings and hence retrieval before deployment. After obtaining the optimal position, the rings are filled with a polymer. The bovine pericardial valve is attached to a cuff that conforms to the annulus. Owing to the speed of deployment, Direct Flow does not require rapid pacing. It provides excellent sealing but suffers from higher gradient. Direct Flow is available only for the transfemoral approach.

The Portico valve (St. Jude Medical, Minneapolis, MN, USA) is a nitinol self-expanding re-sheathable device which consists of bovine pericardial leaflets and a porcine pericardial sealing cuff. It is similar to the Evolut $\mathrm{R}$ and provides open stent cell design to allow access to coronary arteries.

The Symetis Acurate (Symetis SA, Ecublens, Switzerland) is another self-expanding nitinol stent valve with porcine pericardial leaflets which are available for both trans-apical and trans-femoral approaches. This valve has an upper crown for supra-annular anchoring to minimize protrusion into left ventricle and a lower crown that is designed to protrude only minimally into the LVOT. It has inner and outer pericardial skirts to minimize PVL.

The JenaValve (JenaValve Technology $\mathrm{GmbH}$, Munich, Germany) is a self-expanding valve consisting of porcine pericardial leaflets attached to a crown shaped self-expanding nitinol stent. It has three 'feelers' which are to be seated in the aortic sinuses at the base of native leaflets. The feelers in combination with the stent arms in the lower part of the prosthesis allow clipping the native valve leaflets which enable operators to accurately position the prosthesis. Rapid pacing is not required during prosthesis positioning and release. It can be used with both trans-femoral and trans-apical approaches. The clipping mechanism is particularly useful in non-calcified valves or when aortic regurgitation is the primary pathology.

Tables 2 and 3 summarize some features of the commonly available prostheses and their delivery systems.

\section{Potential complications}

\section{Vascular injury}

The risk of significant vascular damage has decreased with lower profile valve delivery systems, but remains around 5-8\%. By default, trans-femoral cases are usually fully percutaneous nowadays when previously the femoral arteriotomy was a direct surgical cut-down. The omission of these traumatic surgical steps have meant that patients can undergo TAVI under conscious sedation as oppose to general anaesthesia and there is a general trend towards a less invasive, conscious sedation approach across the world. The fully percutaneous approach, including ultrasound-guided puncture of the femoral artery and the use of pre-closure suture systems have also refined the technique.

The two main vascular closure devices (VCD) that have been used in TAVI are the ProStar XL (Abbott, Vascular, Santa Clara, California) and PerClose ProGlide (Abbott, Vascular, Santa Clara, California). These are suture-based devices and they replicate surgical closure. The devices were tested in interventional radiology randomized clinical trials that concluded their safe and effective use and non-inferiority to open surgical cut-down (PEVAR trial [15]).

In TAVI, the use of VCD improved procedure safety and reduced complications, however the 
Table 2. Prostheses types and their main advantages (according to manufancturer).

\begin{tabular}{|c|c|c|c|c|}
\hline Device & Manufacturer & Size [mm] & Deployment & Main advantage \\
\hline Sapien XT & $\begin{array}{l}\text { Edwards } \\
\text { Lifesciences }\end{array}$ & $20-29$ & Balloon expandable & Studied in large scale trials \\
\hline Sapien S3 & $\begin{array}{l}\text { Edwards } \\
\text { Lifesciences }\end{array}$ & $20-29$ & Balloon expandable & $\begin{array}{l}\text { Low profile delivery system } \\
\text { Distal skirt that reduces PVL }\end{array}$ \\
\hline CoreValve & Medtronic & $23-31$ & Self-expanding & Studied in large trials \\
\hline CoreValve Evolut R & Medtronic & $23-29$ & Self-expanding & Low profile delivery system \\
\hline Lotus Valve & Boston Scientific & $23-27$ & $\begin{array}{l}\text { Mechanical } \\
\text { expansion }\end{array}$ & $\begin{array}{c}\text { Repositionable } \\
\text { and retrievable valve }\end{array}$ \\
\hline Portico & St. Jude Medical & $23-25$ & Self-expanding & $\begin{array}{c}\text { Low profile delivery system } \\
\text { Repositionable } \\
\text { and retrievable valve }\end{array}$ \\
\hline Direct Flow & $\begin{array}{l}\text { Direct Flow } \\
\text { Medical }\end{array}$ & $25-29$ & $\begin{array}{l}\text { Inflatable aortic and } \\
\text { ventricular rings }\end{array}$ & $\begin{array}{l}\text { Optimal control } \\
\text { over deployment }\end{array}$ \\
\hline CENTERA & $\begin{array}{l}\text { Edwards } \\
\text { Lifesciences }\end{array}$ & $23-26$ & $\begin{array}{l}\text { Motorised } \\
\text { expansion }\end{array}$ & $\begin{array}{l}\text { Ultra-low profile } \\
\text { delivery system }\end{array}$ \\
\hline
\end{tabular}

$\mathrm{PVL}$ - paravalvular aortic leak

Table 3. Examples of some of the available delivery systems.

\begin{tabular}{lccc}
\hline Prosthesis & Size $[\mathrm{mm}]$ & Delivery system & Femoral sheath size \\
\hline Sapien XT & 20 & NovaFlex & 16 Fr eSheath \\
Sapien S3 & 23 & Commander & 14 Fr eSheath \\
& 26 & Commander & 14 Fr eSheath \\
CoreValve & 29 & Commander & 16 Fr eSheath \\
& 23 & DCS-C4-18FR-23 & $18 \mathrm{Fr}$ \\
Evolut R & $26-31$ & DCS-C4-18FR & $18 \mathrm{Fr}$ \\
Lotus & $23-29$ & EnVeo R 14Fr-eqivalent & $14 \mathrm{Fr}$ \\
& 23 & Lotus valve system & $18 \mathrm{Fr}$ \\
Portico & $26-29$ & Lotus valve system & $20 \mathrm{Fr}$ \\
Direct Flow & $23-25$ & Portico TF delivery system & $18 \mathrm{Fr}$ \\
\hline
\end{tabular}

data on the best VCD in TAVI is still contradictory. An awareness of potential harm with check angiography and 'cross-over' access from the contralateral side has improved safety in this regard. The current evidence is that the use of VCDs has a learning curve and in experienced hands they are effective, reduce complications and are likely to influence early mobility and discharge of TAVI patients $[16,17]$.

\section{Paravalvular aortic leak}

Paravalvular aortic leak is an important complication of TAVI that is associated with increased mortality for both balloon-expandable and selfexpanding valves. In early series, TAVI was as- sociated with PVL in more than $80 \%$ of patients. PVL was common with earlier valve designs as a result of incomplete apposition of the prosthesis to the aortic annulus. The principal contributing mechanisms were undersized prostheses, suboptimal positioning and/or challenging anatomy of the aortic root and valve (e.g. eccentric or heavy calcification).

The incidence of moderate or severe PVL has been reported to be between $2 \%$ and $17 \%$ in randomized trials and major registries. Many studies have shown that PVL predicts increased mortality $[18,19]$ and have emphasized that it should be minimized or avoided if at all possible. More sophisticated aortic annulus sizing (with 3D imaging 
Table 4. Rate of complications as per trials and registries.

\begin{tabular}{|c|c|c|c|c|c|c|}
\hline & Year & CVA & Pacing & Vascular & Bleeding & AKI \\
\hline \multicolumn{7}{|l|}{ Trial } \\
\hline PARTNER B [31] & 2010 & $6.7 \%$ & $3.4 \%$ & $30.7 \%$ & $16.8 \% \$$ & 0 \\
\hline PARTNER A [32] & 2011 & $5.5 \%$ & $3.8 \%$ & $17 \%$ & $9.3 \% \$$ & $1.2 \%$ \\
\hline CoreValve Extreme Risk [33] & 2014 & $4 \%$ & $21.6 \%$ & $8.2 \%$ & $12.7 \% *$ & $11.8 \%$ \\
\hline CoreValve High Risk [34] & 2014 & $4.9 \%$ & $19.8 \%$ & $5.9 \%$ & $13.6 \%$ * & $6 \%$ \\
\hline PARTNER II [35] & 2016 & $6.4 \%$ & $8.5 \%$ & $7.9 \%$ & $10.4 \% *$ & $1.3 \%$ \\
\hline NOTION [36] & 2015 & $2.8 \%$ & $34.1 \%$ & $5.6 \%$ & $11.3 \%$ & $0.7 \%$ \\
\hline \multicolumn{7}{|l|}{ Registry } \\
\hline FRANCE II [8] & 2012 & $4.1 \%$ & $15.6 \%$ & $4.7 \%$ & $1.2 \% *$ & $N / R$ \\
\hline UK TAVI [6] & 2016 & $2.6 \%$ & $10.2 \%$ & $3.5 \%$ & $\mathrm{~N} / \mathrm{R}$ & $N / R$ \\
\hline STS/AAC* [9] & $2014^{\wedge}$ & $2.2 \%$ & $11 \%$ & $4.2 \%$ & $4.3 \%$ & $2.2 \%$ \\
\hline $\mathrm{GARY}^{\#}[7]$ & 2015 & $1.5 \%$ & $17.5 \%$ & $4.1 \%$ & $26.3 \%$ & $\mathrm{~N} / \mathrm{R}$ \\
\hline $\operatorname{Asian}^{\#}[10]$ & 2016 & $3.8 \%$ & $9.5 \%$ & $5 \% \$$ & $6.4 \% *$ & $3.3 \%$ \\
\hline Australian-New Zealand [37] & 2014 & $5.3 \%$ & $28.4 \%$ & $7.6 \%$ & $7 \%$ & $6.5 \%$ \\
\hline
\end{tabular}

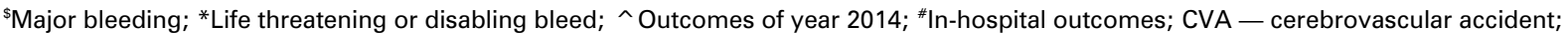
$\mathrm{AKI}$ - acute kidney injury; N/R - not reported

modalities), various technological advances, such as the addition of a 'sealing' skirt to the frame of the valve as with Sapien 3, and judicious use of postdilatation are examples of the concerted efforts to tackle this particular complication. Further studies are needed to verify exactly why paravalvular aortic regurgitation has such a negative effect on survival.

\section{Permanent pacemaker requirement}

The risk of significant conduction disturbance following TAVI is $10-25 \%$. The incidence is variable for different devices as some have a higher pacemaker requirement with the valves than others [20,21]. This has been addressed with device design and also positioning within the native aortic valve. There is some evidence to suggest that a higher prosthesis implantation lessens the incidence of complete heart block [20].

\section{Stroke}

The incidence of stroke after TAVI is between $1.7 \%$ and $8.4 \%$ depending on the clinical definition. Strokes after TAVI may differ in nature from those after sAVR. It is possible that showers of cerebral emboli at different time-points during TAVI cause a more diffuse brain injury manifesting as a subtle cognitive impairment rather than an overt neurological event such as hemiplegia. These kinds of events are difficult to diagnose and indeed adjudicate in clinical trials.

There are a number of cerebral 'embolic protection/deflection' devices currently available to reduce the risk of cerebral micro-embolization. The application of these devices requires extra caution and is only advised in certain high risk groups of patients.

\section{Ventricular injury}

Left and right ventricular injury peri-procedurally is well documented. Whilst the injury is usually traumatic, coronary obstruction as a cause of ventricular injury (peri-procedural myocardial infarction) has also been referred to, the rate of which is less than $1 \%$ [22]. Right ventricular injury is commonly caused by the temporary pacing wire perforation, and left ventricular injury is caused by the stiff wire perforation but a much rarer complication. Traumatic left or right ventricular injury usually manifests itself with pericardial effusion and tamponade. The rate of pericardial effusion and tamponade peri-TAVI is reported to be around $4 \%[23,24]$. Of note, in a series of cases, only 4 (23.5\% of all causes of tamponade) were attributed to direct left ventricular wire perforation [24].

Overall, the complication rate associated with TAVI is decreasing with the advancement of technology and accumulating experience. The rates of stroke, bleeding and vascular complications in real life registries appear to be lower than that of the trials. The rates are likely to drop further once TAVI is performed more in intermediate risk patients. Table 4 lists the reported complications according to the corresponding trial and registry. 
Table 5. A summary of the major completed transcatheter aortic valve implantation (TAVI) trials.

\begin{tabular}{|c|c|c|c|c|c|}
\hline Randomised trial & Objective & Patients & Prosthesis & Year & Outcome \\
\hline PARTNER B & $\begin{array}{l}\text { TAVI superior to } \\
\text { optimal medical } \\
\text { therapy in non-operable } \\
\text { severe AS patients }\end{array}$ & 358 & Edwards Sapien & 2010 & $\begin{array}{l}\text { Significant reduction } \\
\text { in mortality and } \\
\text { hospitalization }\end{array}$ \\
\hline PARTNER A & $\begin{array}{l}\text { TAVI is non-inferior } \\
\text { to sAVR in high risk } \\
\text { surgical patients }\end{array}$ & 699 & Edwards Sapien & 2011 & $\begin{array}{l}\text { TAVI and SAVR have } \\
\text { similar rates of } \\
\text { mortality at } 1 \text { year }\end{array}$ \\
\hline PARTNER 2 & $\begin{array}{l}\text { TAVI is non-inferior to } \\
\text { sAVR in intermediate } \\
\text { risk patients }\end{array}$ & 2032 & $\begin{array}{l}\text { Edwards } \\
\text { Sapien XT }\end{array}$ & 2016 & $\begin{array}{l}\text { TAVI is non-inferior } \\
\text { in terms of mortality } \\
\text { and stroke }\end{array}$ \\
\hline $\begin{array}{l}\text { CoreValve Pivotal } \\
\text { high risk trial }\end{array}$ & $\begin{array}{l}\text { TAVI is non-inferior } \\
\text { and superior to sAVR }\end{array}$ & 795 & CoreValve & 2014 & $\begin{array}{l}\text { TAVI is superior } \\
\text { to sAVR }\end{array}$ \\
\hline $\begin{array}{l}\text { CoreValve Pivotal } \\
\text { extreme risk trial }\end{array}$ & $\begin{array}{l}\text { TAVI is superior to } \\
\text { optimal medical therapy }\end{array}$ & 506 & CoreValve & 2014 & $\begin{array}{l}\text { TAVI is safe and } \\
\text { effective }\end{array}$ \\
\hline NOTION trial & $\begin{array}{l}\text { TAVI is non-inferior to } \\
\text { sAVR in all comers }\end{array}$ & 280 & CoreValve & 2015 & $\begin{array}{c}\text { TAVI is non-inferior } \\
\text { to sAVR }\end{array}$ \\
\hline DEFLECT III trial [38] & $\begin{array}{l}\text { TriGuard cerebral } \\
\text { protection evaluation }\end{array}$ & 85 & $\begin{array}{l}\text { Edwards Sapien } \\
\text { and CoreValve }\end{array}$ & 2015 & $\begin{array}{c}\text { TriGuard is safe and } \\
\text { effective }\end{array}$ \\
\hline BRAVO-3 trial [39] & $\begin{array}{c}\text { Bivalirudin vs. heparin } \\
\text { in TAVI }\end{array}$ & 802 & Multiple & 2015 & $\begin{array}{l}\text { Bivalirudin does not } \\
\text { reduce bleeding }\end{array}$ \\
\hline EMBOL-X [40] & $\begin{array}{c}\text { Intra-aortic protection } \\
\text { device }\end{array}$ & 30 & Sapien XT & 2015 & $\begin{array}{l}\text { Reduced cerebral } \\
\text { lesions }\end{array}$ \\
\hline
\end{tabular}

AS - aortic stenosis; sAVR - surgical aortic valve replacement

Table 6. Unpcoming randomised clinical trials in transcatheter aortic valve implantation (TAVI).

\begin{tabular}{|c|c|c|}
\hline Trial & Objective & Date of completion \\
\hline PARTNER 3 & $\begin{array}{l}\text { To determine safety and effectiveness of Sapien } 3 \text { in low risk } \\
\text { patients in comparison to sAVR }\end{array}$ & 2027 \\
\hline UK TAVI & $\begin{array}{l}\text { To determine clinical effectiveness and cost-utility of TAVI } \\
\text { in comparison to sAVR (high and intermediate risk) }\end{array}$ & 2016 \\
\hline ACTIVATION & Percutaneous coronary intervention prior to TAVI & \\
\hline GALILEO & $\begin{array}{l}\text { Effect of rivaroxaban anticoagulation strategy in comparison } \\
\text { to dual anti-platelet therapy }\end{array}$ & 2018 \\
\hline TAVR UNLOAD & $\begin{array}{l}\text { To determine safety and efficacy of TAVI in patients with } \\
\text { moderate aortic stenosis and heart failure in comparison } \\
\text { to optimal medical therapy }\end{array}$ & 2020 \\
\hline $\begin{array}{l}\text { STEP for patients } \\
\text { prior to undergoing } \\
\text { TAVR }\end{array}$ & $\begin{array}{l}\text { Whether supervized exercise would improve frailty status } \\
\text { of TAVI patients }\end{array}$ & 2017 \\
\hline
\end{tabular}

sAVR - surgical aortic valve replacement; TAVR — transcatheter aortic valve replacement

\section{Current evidence}

The number of randomized trials involving TAVI is rising, and whilst initially the main objectives of the trials were to demonstrate its noninferiority to sAVR, current trials also compare different strategies in TAVI (Table 5). These randomized trials thus far have certainly demonstrated non-inferiority to sAVR in terms of mortality and stroke in high and intermediate risk patients and superiority to optimal medical therapy.

\section{Upcoming trials}

Table 6 shows examples of the upcoming randomized clinical trials in TAVI [25]. The topics and the research questions that are being asked have 
Table 7. Reported registries' outcome.

\begin{tabular}{|c|c|c|c|c|c|}
\hline Registry & Country & Cases & Year & $\begin{array}{l}\text { Mortality } \\
\text { at } 1 \text { year }\end{array}$ & Stroke \\
\hline FRANCE II & France & 3,195 & 2012 & $24 \%$ & $4.1 \%$ \\
\hline STS/AAC & United States of America & 12,182 & 2015 & $23.7 \%$ & $4.1 \%$ \\
\hline GARY & Germany & 3,876 & 2014 & $24.3 \%$ & $4.2 \%$ \\
\hline UK TAVI & United Kingdom & 3671 & 2015 & $18.3 \%$ & \\
\hline Asian TAVR & Multiple & 848 & 2016 & $10.8 \%$ & $3.8 \%$ \\
\hline Australian-New Zealand & Australia, New Zealand & 540 & 2014 & $11.9 \%$ & $8.2 \%$ \\
\hline
\end{tabular}

varied more recently and ask questions beyond merely demonstrating the efficacy of the technique.

\section{Evidence from registries}

The uptake of TAVI technology is increasing worldwide. Registries around the world are regularly publishing and updating their experience with TAVI. One-year mortality is somehow variable among different countries but the rate of stroke seems more consistent. Both outcome measures have decreased in recent years. Table 7 summarizes the two main outcomes (mortality and stroke) at 1 year reported by these registries according to their most recent publications.

\section{Cost-effectiveness of TAVI}

The debate over cost-effectiveness of TAVI is complicated with the following issues:

- The characteristics of the patients who are deemed suitable for TAVI (high risk elderly patients with multiple comorbidities);

- The life expectancy is relatively short for these patients even with successful treatment;

- The duration of economic modeling;

- The control group (TAVI vs. optimal medical therapy, and TAVI vs. sAVR);

- The healthcare/reimbursement system studied. The index procedure of TAVI is more expensive than sAVR and any cost saving earned is usually through lower cost of hospitalization and follow-up. In the United Kingdom (Aug 2013), TAVI was found to be cost-effective when compared to optimal medical therapy (patients who were unsuitable for sAVR), but more costly and less effective when compared to sAVR (patients who were suitable for sAVR) [26]. Reynolds et al. [27] studied the PARTNER A cohort and concluded that trans-femoral TAVI was an attractive option when compared to sAVR but not transapical TAVI. When self-expanding prosthesis TAVI was compared to sAVR (CoreValve US. pivotal trial cohort), the authors concluded that TAVI provided meaningful clinical benefits with incremental costs considered acceptable by United States standards [28].

In summary, TAVI seems cost-effective when compared to medical therapy. Trans-femoral TAVI also seems cost-effective when compared to sAVR. It is very likely that the tide will shift in favour of TAVI when competition for alternative devices drives down device prices.

\section{What lies ahead?}

Arguably, the most frequently asked question in the TAVI arena is what happens to these prostheses long-term?

Dvir et al. [29] reported crude data in 2016 which suggested a $50 \%$ prosthesis degeneration rate within 8 years of implant. However, the number of cases at risk in the study was only 43 at 6 years and only 7 cases at 8 years. The jury is still out on this and future publications have much to add. The general feeling in the cardiology community is that TAVI prostheses are as durable a surgical bioprostheses although further research on this subject is eagerly awaited.

Considering recent results of PARTNER II and other intermediate risk studies such as UK TAVI and SURTAVI, it is very likely that the indications of TAVI will expand to cover intermediate risk patients, thus increasing the number of TAVIs worldwide even further. The expected increase in the uptake of TAVI will be consolidated by lower profile delivery systems, and predictable, repositionable and retrievable prostheses.

On the other hand, clinical practice simplification of the procedure (such as the introduction of conscious sedation, fully percutaneous approach and early mobility post TAVI) is likely to increase early discharge rates [30]. This approach is likely to make TAVI an even more cost-effective technique and more appealing to patients who are usually keen for quick recovery after a procedure. 
Unanswered questions about co-morbidities such as co-existing coronary artery disease, mitral valve disease and pulmonary hypertension are likely to be clarified in the near future by further research (randomized and observational).

Finally, much of TAVI technology and experience is being utilized in the development of trans-catheter mitral valve interventions, the long-waited and expected next era of trans-catheter intervention.

\section{Conclusions}

Transcatheter aortic valve implantation is now a well-established therapy for aortic valve disease. The procedure is being simplified, the complication rate is being reduced and indications are expanding. It is an increasingly cost-effective treatment and is likely to become a first line option in the treatment of AS, particularly as device costs fall in the years to come.

\section{Conflict of interest: None declared}

\section{References}

1. Mortality and life expectancy statistics in Europe. http://ec.europa. eu/eurostat/statistics explained/index.php/Mortality_and_life_expectancy_statistics.

2. d'Arcy JL, Prendergast BD, Chambers JB, et al. Valvular heart disease: the next cardiac epidemic. Heart. 2011; 97(2): 91-93, doi: 10.1136/hrt.2010.205096, indexed in Pubmed: 21149862.

3. Nkomo VT, Gardin JM, Skelton TN, et al. Burden of valvular heart diseases: a population-based study. Lancet. 2006; 368(9540): 1005-1011, doi: 10.1016/S0140-6736(06)69208-8, indexed in Pubmed: 16980116.

4. Vahanian A, Alfieri O, Andreotti F, et al. [Guidelines on the management of valvular heart disease (version 2012). The Joint Task Force on the Management of Valvular Heart Disease of the European Society of Cardiology (ESC) and the European Association for Cardio-Thoracic Surgery (EACTS)]. G Ital Cardiol (Rome). 2013; 14(3): 167-214.

5. Nishimura RA, Otto CM, Bonow RO, et al. 2014 AHA/ACC Guideline for the Management of Patients With Valvular Heart Disease: a report of the American College of Cardiology/American Heart Association Task Force on Practice Guidelines. Circulation. 2014; 129(23): e521-e643.

6. Ludman PF, Moat N, Belder MA de et al. Transcatheter aortic valve implantation in the United Kingdom: temporal trends, predictors of outcome, and 6-year follow-up: a report from the UK Transcatheter Aortic Valve Implantation (TAVI) Registry, 2007 to 2012. Circulation. 2015; 131(13): 1181-1190.

7. Walther T, Hamm CW, Schuler G, et al. GARY Executive Board. Perioperative Results and Complications in 15,964 Transcatheter Aortic Valve Replacements: Prospective Data From the GARY Registry. J Am Coll Cardiol. 2015; 65(20): 2173-2180, doi: 10.1016/j.jacc.2015.03.034, indexed in Pubmed: 25787198.
8. Gilard M, Eltchaninoff H, Lung B. Registry of Transcatheter Aortic-Valve Implantation in High-Risk Patients. J Vasc Surg. 2012; 56(4): 1180-1181, doi: 10.1016/j.jvs.2012.08.054.

9. Holmes D, Nishimura R, Grover F, et al. Annual outcomes with transcatheter valve therapy. J Am Coll Cardiol. 2015; 66(25): 2813-2823, doi: 10.1016/j.jacc.2015.10.021.

10. Yoon S, Ahn J, Hayashida K, et al. Clinical outcomes following transcatheter aortic valve replacement in Asian populationn. JACC Cardiovasc Interv. 2016; 9(9): 926-933, doi: 10.1016/j. jcin.2016.01.047.

11. Eggebrecht H, Mehta RH. Transcatheter aortic valve implantation (TAVI) in Germany 2008-2014: on its way to standard therapy for aortic valve stenosis in the elderly? EuroIntervention. 2016; 11(9): 1029-1033, doi: 10.4244/EIJY15M09_11, indexed in Pubmed: 26384006.

12. Mylotte D, Osnabrugge R, Windecker S, et al. Transcatheter Aortic Valve Replacement in Europe. J Am Coll Cardiol. 2013; 62(3): 210-219, doi:10.1016/j.jacc.2013.03.074.

13. Rampat R, Khawaja MZ, Byrne J, et al. Transcatheter aortic valve replacement using the repositionable LOTUS valve: United Kingdom Experience. JACC Cardiovasc Interv. 2016; 9(4): 367-372, doi: 10.1016/j.jcin.2015.12.012, indexed in Pubmed: 26892082.

14. Eksik A, Yildirim A, Gul M, et al. Comparison of Edwards Sapien XT versus Lotus Valve Devices in Terms of Electrophysiological Study Parameters in Patients Undergoing TAVI. Pacing Clin Electrophysiol. 2016; 39(10): 1132-1140, doi: 10.1111/ pace.12917, indexed in Pubmed: 27418419.

15. Nelson PR, Kracjer Z, Kansal N, et al. A multicenter, randomized, controlled trial of totally percutaneous access versus open femoral exposure for endovascular aortic aneurysm repair (the PEVAR trial). J Vasc Surg. 2014; 59(5): 1181-1193, doi: 10.1016/j.jvs.2013.10.101, indexed in Pubmed: 24440678.

16. Hayashida K, Lefevre T, Chevalier B, et al. True percutaneous approach for transfemoral aortic valve implantation using the Prostar XL device: impact of learning curve on vascular complications. JACC Cardiovasc Interv. 2012; 58(20): 207-214, doi: 10.1016/j.jcin.2011.09.020.

17. Dimitriadis $Z$, Scholtz W, Börgermann J, et al. Impact of closure devices on vascular complication and mortality rates in TAVI procedures. Int J Cardiol. 2017 [Epub ahead of print], doi: 10.1016/j. ijcard.2017.01.088, indexed in Pubmed: 28153535.

18. Lerakis S, Hayek SS, Douglas PS. Paravalvular aortic leak after transcatheter aortic valve replacement: current knowledge. Circulation. 2013; 127(3): 397-407, doi: 10.1161/CIRCULATIONAHA.112.142000, indexed in Pubmed: 23339094.

19. Dworakowski R, Wendler O, Halliday B, et al. Device-dependent association between paravalvar aortic regurgitation and outcome after TAVI. Heart. 2014; 100(24): 1939-1945, doi: 10.1136/ heartjnl-2013-305390, indexed in Pubmed: 25053724.

20. Bleiziffer S, Ruge H, Horer J, et al. Predictors for new-onset complete heart block after transcatheter aortic valve implantation. JACC Cardiovasc Interv. 2010; 3(5): 524-530.

21. Ferreira ND, Caeiro D, Adão L, et al. Incidence and predictors of permanent pacemaker requirement after transcatheter aortic valve implantation with a self-expanding bioprosthesis. Pacing Clin Electrophysiol. 2010; 33(11): 1364-1372, doi: 10.1111/j.1540-8159.2010.02870.x, indexed in Pubmed: 20723083.

22. Aldalati O, MacCarthy P. Further refining the technique: new concepts in TAVI research. EuroIntervention. 2015; 11(5): 497-501. 
23. Katsanos S, van Rosendael P, Kamperidis V, et al. Pericardial effusion following transcatheter aortic valve implantation: echocardiography and multi-detector row computed tomography evaluation. Int J Cardiovasc Imaging. 2015; 31(1): 37-43.

24. Rezq A, Basavarajaiah S, Latib A, et al. Incidence, management, and outcomes of cardiac tamponade during transcatheter aortic valve implantation: a single-center study. JACC Cardiovasc Interv. 2012; 5(12): 1264-1272.

25. https://clinicaltrials.gov/ct2/results?term=TAVR\&Search=Search.

26. Orlando R, Pennant M, Rooney S, et al. Cost-effectiveness of transcatheter aortic valve implantation (TAVI) for aortic stenosis in patients who are high risk or contraindicated for surgery: a modelbased economic evaluation. Health Technol Assess. 2013; 17(33): 1-86, doi: 10.3310/hta17330, indexed in Pubmed: 23948359.

27. Reynolds MR, Magnuson EA, Lei Y, et al. Cost-effectiveness of transcatheter aortic valve replacement compared with surgical aortic valve replacement in high-risk patients with severe aortic stenosis: results of the PARTNER (Placement of Aortic Transcatheter Valves) trial (Cohort A), J Am Coll Cardiol. 2012; 60(25): 2683-2692, doi: 10.1016/j.jacc.2012.09.018.

28. Reynolds MR, Lei Y, Wang K, et al. CoreValve US High Risk Pivotal Trial Investigators. Cost-Effectiveness of Transcatheter Aortic Valve Replacement With a Self-Expanding Prosthesis Versus Surgical Aortic Valve Replacement. J Am Coll Cardiol. 2016; 67(1): 29-38, doi: 10.1016/j.jacc.2015.10.046, indexed in Pubmed: 26764063.

29. Dvir D. First look at long-term durability of transcatheter heart valves: assessment of valve function up to 10 years after implantation; Oral presentation, EuroPCR, Paris 2016.

30. Durand E, Eltchaninoff H, Canville A, et al. Feasibility and safety of early discharge after transfemoral transcatheter aortic valve implantation with the Edwards SAPIEN-XT prosthesis. Am J Cardiol. 2015; 115(8): 1116-1122, doi: 10.1016/j.amjcard.2015.01.546, indexed in Pubmed: 25726383.

31. Leon MB, Smith CR, Mack M, et al. Transcatheter aorticvalve implantation for aortic stenosis in patients who cannot undergo surgery. N Engl J Med. 2010; 363(17)(12): 1597-1607, doi: 10.1056/NEJMoa1008232.
32. Smith CR, Leon MB, Mack MJ, et al. Transcatheter versus surgical aortic-valve replacement in high-risk patients. N Engl J Med. 2011; 364(23): 2187-2198.

33. Popma J, Adams D, Reardon M, et al. Transcatheter aortic valve replacement using a self-expanding bioprosthesis in patients with severe aortic stenosis at extreme risk for surgery. J Am Coll Cardiol. 2014; 63(19): 1972-1981, doi: 10.1016/j.jacc.2014.02.556.

34. Adams DH, Popma JJ, Reardon MJ et al. Transcatheter or Surgical Aortic-Valve Replacement in Intermediate-Risk Patients. N Engl J Med. 2014; 370(19): 1790-1798.

35. Leon MB, Smith CR, Mack M, et al. Transcatheter or surgical aortic-valve replacement in intermediate-risk patients. N Engl J Med. 2016; 374(17): 1609-1620.

36. Thyregod H, Steinbruchel DA, Ihlemann N, et al. Transcatheter versus surgical aortic valve replacement in patients with severe aortic valve stenosis: 1-year results from the All-Comers NOTION Randomized Clinical Trial. J Am Coll Cardiol. 2015; 65(20): 2184-2194, doi: 10.1016/j.jacc.2015.03.014., indexed in Pubmed: 9015094.

37. Meredith IT, Walton A, Walters DL, et al. Mid-term outcomes in patients following transcatheter aortic valve implantation in the CoreValve Australia and New Zealand Study. Heart Lung Circ. 2015; 24(3): 281-290, doi: 10.1016/j.hlc.2014.09.023, indexed in Pubmed: 25456213.

38. Lansky AJ, Schofer J, Tchetche D, et al. A prospective randomized evaluation of the TriGuard ${ }^{\mathrm{TM}} \mathrm{HDH}$ embolic DEFLECTion device during transcatheter aortic valve implantation: results from the DEFLECT III trial. Eur Heart J. 2015; 36(31): 2070-2078, doi: 10.1093/eurheartj/ehv191, indexed in Pubmed: 25990342.

39. Dangas G, Lefèvre T, Kupatt $\mathrm{C}$, et al. Bivalirudin versus heparin anticoagulation in transcatheter aortic valve replacement. J Am Coll Cardiol. 2015; 66(25): 2860-2868, doi: 10.1016/j. jacc.2015.10.003.

40. Wendt D, Kleinbongard P, Knipp S, et al. Intraaortic protection from embolization in patients undergoing transaortic transcatheter aortic valve implantation. Ann Thorac Surg. 2015; 100(2): 686-691, doi: 10.1016/j.athoracsur.2015.03.119, indexed in Pubmed: 26234838 . 